\title{
Measuring of Soft Power: The Case of Belarus
}

\author{
Olena Primierova ${ }^{1, *}$ and Juliet Abakumova ${ }^{2}$ \\ ${ }^{1}$ National university of Kyiv-Mohyla academy, Faculty of Economics, Department of Finance, \\ Skovorody 2, 04070 Kyiv, Ukraine \\ ${ }^{2}$ Belarusian state university, Economics Faculty, Department of Analytical Economics and \\ Econometrics, K.Marks 31, 220030 Minsk, Belarus
}

\begin{abstract}
Research background: With the processes of globalization in the modern world is inextricably interlinked the growing role of non-force methods in foreign policy, as well as the increased attention of the leaders of all leading states to improving the image and increasing the attractiveness of their country, which is directly related to the concept of soft power. To assess the degree of use of soft power in the foreign policy, various ratings are currently being constructed based on the analysis of public opinion, expert assessments, and the estimation of integral quantitative indicators. The data incomparability, as well as the subjective nature and not always adequate results of assessing public opinion, often lead to ratings inconsistency. In addition, Belarus is not included in most of the ratings.

Purpose of the article: Assessment of the potential of soft power concept use for Belarus, in particular, based on the development of an integral indicator of the country's image and popularity.

Methods: The methodology of the Moscow School of Management Skolkovo and the British audit and consulting company Ernst and Young. When constructing the integral indicator, the principal component analysis and the ordered multiple-choice were also used.

Findings \& Value added: The assumption about the inconsistency between the considered soft power ratings was confirmed. Based on the results of the assessment of the soft power index and the integral indicator, it was concluded that Belarus can be classified as a country with an average level of potential for the use of soft power instruments.
\end{abstract}

Keywords: soft power; country image; nation branding; soft power measurement; integral indicator.

JEL Classification: $C 00 ; F 59 ; F 69$

*Corresponding author: o.primierova@ukma.edu.ua 


\section{Introduction}

\subsection{Soft power}

At the moment, there is a tendency towards globalization in the world, which entails the world unification of states along with the economic, political and cultural spheres. In the process of globalization, countries are striving to benefit from this process. One of the ways is to increase the level of trust in the country, and governments use the concept of soft power to achieve the desired effect. Of course, soft power is not the solution to all the problems of the world; both advantages and disadvantages can be noted. For example, the ideology of soft power itself and its possible use can be nothing more than a distraction for the implementation of a policy of hard power on the part of certain states. Sometimes the results of the pursued soft power policy are quite controversial for the target-country (Schulze, 2021). Often, countries that are actively developing a soft power strategy lead in terms of military power, which is an instrument of hard power. However, the effective use of soft power tools makes it possible to create the illusion (and sometimes reality) of mutual interest, respect, trust, mutual understanding, and on this basis it becomes possible to form the influence of a given state on humanitarian and political processes in the world and in specific countries. It can be said that the development of a strategy for the use of soft power tools is within the sphere of interests of practically every country, and it is certainly necessary to recognize the presence of certain positive effects.

The concept of soft power was developed in the work of Joseph S. Nye (2011) and many other scientists, whose articles are aimed at both a critical analysis of Nye's ideas (Ying, 2008) and the study of the features of the soft power of various countries. It is possible to single out an extensive class of publications that are devoted to the discussion of the problems of measuring soft power, analysis, comparison and criticism of international ratings. It seems interesting, for example, to consider the comparison the Portland Soft Power 30 Index and the China National Image Global Survey in (Zhang and Wu, 2019), which analyzes the differences in the assessments of soft power by Western organizations and the China Survey.

To some extent, it is possible to classify publications that analyze the impact of the national brand and the choice of soft power strategy on various aspects of society and the economy of the country. Considering that in many ways, when developing a soft power strategy, countries are interested in an effective foreign trade policy, the effect of soft power on exports is often analyzed. That is, researchers find evidence that the countries receive a commercial return on their soft power. From recent publications, we can mention (Wagner, 2020), where, based on the gravity model, the results of assessing the effect of soft power were obtained, which confirm that exports are influenced by how the population in the importing countries treats the leadership and policies of the exporting country. Earlier A. Rose also obtained similar results based on gravity models. In one case, the results of the annual survey conducted for the BBC by GlobeScan (Rose, 2016) were used as estimates of attitudes towards countries, and in the other - the annual Gallup survey (Rose, 2019). According to the results of evaluating the models, country's exports are higher if it's perceived by the importer to be exerting more positive global influence, so we can say that countries receive a commercial return on their soft power. Didier (2019) used a gravity model and data from two proxies with the BBC-GlobeScan and Pew surveys about people's opinion on exporter countries. Confirming the effect of soft power on exporting firms behaviors, the author specifies that the results will be more significant in the case of developing countries and analysis of aggregate level of trade.

If we go from economy to society, then publications devoted to assessing the impact on the image of the state of the success of diplomacy, the development of the export of educational services and the formation of the knowledge economy, as well as sports 
achievements in international competitions, are of interest. In (Laifer and Kitchen, 2017), the problem of using soft power at the intersection of diplomacy and education is analyzed, namely, the promotion of the education system in the Asian market, with an emphasis not only on quality, but also through the components of Australia's attractiveness as a country, i.e. creating a positive attitude. Although we can say that Belarus is actively using this instrument of soft power, increasing the export of educational services, however, there are no publications on this topic. In (Lo, 2011) that the emerging global university rankings are important resources of soft power that have the potential, as a governance tool, to reshape the global higher education landscape. Although the results of Belarus in this direction are still rather modest, certain positive results have been achieved in recent years. When it comes to the impact of sports on a national brand, people tend to try to quantify. Strożek and Kobierecki (2017) analyzed the relationship between Olympic achievements and the available brand ratings for a country. In the few publications in this area, dedicated to Belarus, as a rule, the relationship between the holding of sporting events and the growth of the country's recognition rates in the world is analyzed.

\subsection{Soft power measurements}

The growing interest in the concept of soft power in society and among researchers gave rise to attempts to measure soft power, which led to the creation of ratings of soft power and the development of various methods for its assessment. Initially, the author of the concept only singled out a number of indicators by which one can judge that the country has certain resources of soft power, but did not offer formalized assessment methods (Nye, 2004). Nye suggested assessing the degree of the impact of soft power by its result: whether an attractive image of the country has developed in the eyes of the international community, whether its policy is legitimate, and the values are shared by everyone. The researchers initially moved in this direction when measuring the soft power of the country: they conducted public opinion polls and analyzed the results. However, then research began to be intensively conducted in the field of rating measurements of soft power and its indexing. Both analytical centers and consulting companies and individual scientists began to deal with quantitative methods of measuring soft power. Initially, when developing parameters and indices of soft power, they began to distinguish five of its main varieties: political, cultural, diplomatic, economic and humanitarian. Then these measurement parameters were averaged and presented as a global soft power index. Rating assessments of the using of soft power instruments in the foreign policy of various states began to be based on the analysis of public opinion, expert assessments and calculations of integral quantitative indicators.

The analysis of public opinion, for example, underlies the construction of the rating of the attractiveness of states, built by the RAND Corporation and taking into account the answers of respondents to the question of which country, if not their own, they would like to live. Examples of expert assessments of soft power are country ratings based on Anholt-GfK Roper Nation Brands Index and The Good Country Index. Taking into account both public opinion polls and the opinion of experts, the global soft power index of the British transnational consulting company Brand Finance is being built. The index takes into account a wide range of soft power tools to assess the presence of nations, reputation and influence on the world stage. Business and trade, governance, international relations, culture and heritage, media and communications, education and science, people and values are considered as the main components of soft power. Еще один известный апробированный индикатор - Country Brand Index, developed and calculated every few years. It is published by the international consulting company Future Brand. During the last study, about 2500 experts from 75 countries included in the rating were interviewed.

Over time, different scientists, for example, A. Hunter (2009), began to realize the need for a more detailed and in-depth development of a methodologically grounded set of 
parameters for assessing soft power. Thus, in 2010, the first large-scale attempt was made to compile a rating of the soft power of the countries of the world on the basis of subjective and objective indicators. The creators of the rating are Monocle magazine and The Institute for Government, a British independent charitable organization. The construction of a quantitative indicator of the rating assessment of soft power, taking into account statistical data, was undertaken by Ernst \& Young in cooperation with the Moscow Institute for the Emerging Market Studies «Skolkovo» - Rapid-growth markets soft power index Spring 2012. The ratings that take into account both objective and subjective factors include The Soft Power 30, developed by an international consulting company Portland.

The position of countries in the rankings is directly dependent on the chosen criteria, and the perception of a country's soft power may differ in different regions, societies and cultures. Therefore, the estimates obtained can only be relatively objective, and can also be the result of the engaged position of the researchers. The choice of criteria and conclusions based on the results obtained is influenced by such an indicator as the researcher's belonging to a particular culture, from which his beliefs and values follow. The subject of discussion is the use of exclusively quantitative indicators in assessing the effectiveness of soft power instruments and national brands: the use of exclusively statistical indicators can lead to an unsatisfactory result, because the picture of the world described with their help will be incomplete, one-sided. Including additional public opinion polls in the research, on the other hand, they return to the problem of the bias of the results obtained, the engaged estimations of experts, etc.

Also noteworthy is the assessment by authors and researchers of sports, sports achievements of countries when compiling a rating of brand countries. Discussion by the press and analysts of the results of the annual rating of countries in the review of soft power usually boils down to the recognition of the role of the Olympic Movement, the number of Olympic medals is ultimately the reason for the country's move up in the positions of international soft power ratings. Postulating that sport is one of the key resources and active tools in the set of tools of the national soft power, paying tribute to the effectiveness of the achievements of sport in improving the country's image, modern studies are increasingly turning to the analysis of this soft power instrument.

\section{Methods and Results}

\subsection{Checking the consistency of soft power indices}

Conclusions about the inconsistency of international soft power ratings can be based mainly on the discrepancy in the assessment of sub-indices, the choice of different factors in the developing of the rating, or the assignment of different ranks to them when constructing the index. It is also clear that these conclusions will depend on the countries selected for the analysis. This is explained by differences in the positions in the ratings for each country (to a greater extent for those countries that are not included in the top ranking), the possibility of a country not being included in a certain rating as a whole or in a single year, etc. Often, when analyzing, researchers are focused on to data for countries included in the top 10, etc. This also reduces the likelihood of encountering missing (omitted) data, i.e. lack of position for the country in any of the ratings.

Spearman and Kendall rank correlation coefficients can be used to assess the consistency between countries' positions in the ratings, as well as the concordance correlation coefficient to assess the tightness of the relationship for more than two indices at the same time. Initially, the authors selected the countries included in the top 10 according to Brand Finance 2020 for analysis, and then analyzed correlations within the sample, including in order to investigate their stability to change the countries included in the sample. In turn, the change in 
conclusions about the strength of the correlation depending on the choice of countries confirms the assumption of inconsistency in the ratings, just as if these correlations turned out to be statistically insignificant. The rating data for 2019-2020 were considered, respectively: Monocle, Brand Finance and Portland companies, as well as Bloom Consulting (Trade and Tourism Editions). The last Country Brand Ranking was added to consider the possibility of an asymmetric relationship with different groups of factors (and, as can be seen from the results below, the indicators related to Tourism Edition are more related to positions in Brand Finance).

The conclusions based on the results of assessing the rank correlation for the Spearman and Kendall coefficients practically coincided. Here are the values of the rank correlation coefficient and the confidence level of the hypothesis of the statistical insignificance of the coefficient for the first of the tests (Table 1).

Table 1. Spearman rank correlation test between soft power indices.

\begin{tabular}{|l|l|c|c|}
\hline \multicolumn{2}{|c|}{ Soft Power Indices (in pairs) } & $\begin{array}{c}\text { Spearman rank- } \\
\text { order correlation }\end{array}$ & Probability \\
\hline Brand Finance & Monocle & 0.261 & 0.467 \\
\hline Brand Finance & Portland & 0.370 & 0.293 \\
\hline Monocle & Portland & $\mathbf{0 . 5 7 6}$ & $\mathbf{0 . 0 8 2}$ \\
\hline Brand Finance & Bloom Consulting (Trade Ed.) & $\mathbf{0 . 5 5 2}$ & $\mathbf{0 . 0 9 8}$ \\
\hline Monocle & Bloom Consulting (Trade Ed.) & -0.200 & 0.580 \\
\hline Portland & Bloom Consulting (Trade Ed.) & 0.297 & 0.405 \\
\hline Brand Finance & Bloom Consulting (Tourism Ed.) & $\mathbf{0 . 9 0 3}$ & $\mathbf{0 . 0 0 0}$ \\
\hline Monocle & Bloom Consulting (Tourism Ed.) & 0.309 & 0.385 \\
\hline Portland & Bloom Consulting (Tourism Ed.) & 0.442 & 0.200 \\
\hline
\end{tabular}

Source: author

A significant relationship is confirmed only for the pair Brand Finance and Bloom Consulting (Tourism Edition), at a level of $\alpha=0.10$, also we can talk about the rejection of the null hypothesis for the pairs Brand Finance and Bloom Consulting (Trade Edition), Monocle and Portland. The obtained conclusion for the last pair is easily explained by the fact that in their rating the experts of Portland Communication used some of the methodological approaches of the Monocle rating. The main difference was that the assessment of the Portland composite index combined not only subjective data, but also objective data, as well as a digital component.

No rating shows irrefutable results, no index is perfect. In general, based on the analysis of paired rank correlation coefficients, it is impossible to conclude about the consistency of ratings, since either the null hypothesis is rejected at a sufficiently high level of error, or the conclusion depends on the sample and is unstable to newly entered data. We can say that there is no connection between the ratings, and the exception is cases when the ratings are compiled using the same or similar methodological approaches. Therefore, we complement the analysis by checking the consistency of soft power ratings based on the concordance coefficient.

Taking into account the conclusions obtained in the analysis of rank correlation, as well as the peculiarities of calculating the coefficient, we will consider the three main indices (Table 1) for the countries that took the first eight positions in Brand Finance. The value of the concordance coefficient was $\mathrm{W}=0.457$, which confirms the conclusion about the lack of consistency of expert opinions, the confidence probability when testing the hypothesis about the statistical significance of the coefficient was $P=0.21$. When using the coefficient to check the consistency of expert assessments, a sufficient consistency of expert opinions is said when the concordance coefficient exceeds 0.5 . The transition to the consideration of the first seven 
positions of the rating affects our results, since in this case we get $\mathrm{W}=0.683$ and $\mathrm{P}=0.056$, i.e. we can talk about the average degree of consistency of ratings.

Thus, using more indices when analyzing a country's use of soft power instruments provides a more complete view. Based on the result obtained, it is possible to justify the use of a large number of factors from different groups, of an objective and subjective nature, when compiling ratings. Indeed, there are proposals to increase the objectivity of measurements of "soft power" to include indices of country brands in the soft power measurement system, using quantitative methods, expert assessments and content analysis of media sources. The lack of consistency of ratings indicates differences in the approaches used to assess soft power and indicates the need for further work, both on the system of indicators for measuring soft power and on the tools for constructing the rating. There is a need to develop ratings that use different approaches and methodologies implemented in compiling other indices or using such indices as indicators when developing a new rating. Despite the fact that you can find many proposals for the development of such global and transparent ratings (Korolev et al., 2014), currently, when assessing soft power, the already known and mentioned indices are used.

\subsection{Assessment of the integral indicator of the country's image and its openness: case of Belarus}

If we talk about the using of soft power instruments in the case of Belarus, the country demonstrates a desire to work on its image: it takes an active part in international sports events and is ready to host them, provides a platform for negotiations (as in the case of resolving the situation in Ukraine), increases exports educational services, participates in various international programs, etc. At the same time, of course, the positions for which no positive changes are observed are preserved.

When assessing the using of soft power by international ratings, a problem arises due to the fact that Belarus is not included in most ratings. It will not always be correct to focus on the results for Russia, Poland and Ukraine included in these ratings. Let's analyze the results of assessing national brands by Bloom Consulting. In the Country Brand Ranking Belarus took 127th position in the Tourism Edition from 197 countries (40th position from 42 European countries), 88th position in the Trade Edition from 194 countries (30th position from 43 European countries). Despite the best positions in the Trade Edition, Belarus is inferior to both the main members of the EAEU (members of the Customs Union) and the countries of its closest neighbors: Russia (15th position in the world) and Kazakhstan (37), Poland (26) and Ukraine (43). New EAEU members, such as Armenia (140) and Kyrgyzstan (160), as well as the Baltic countries: Lithuania (97), Latvia (100), Estonia (102), lost their positions to Belarus in the Trade edition. In Tourism Edition, of the listed countries, only Kyrgyzstan is ranked below Belarus.

When analyzing without considering positions in international rankings, as a rule, the sports achievements of the country in the international arena, the export of educational services, the openness of the country and indexation in world networks are assessed (Pavlovskaya and Abakumova, 2020). In publications of this kind, as a rule, there are positive trends in assessing the country's image and its openness, but they refer to the pre-pandemic period.

Among the methods of assessing the effectiveness of the use of tools that can be used to compile a rating of countries outside the main international rankings, we can mention the Soft Power Index, developed in 2012 by the Moscow School of Management Skolkovo and Ernst and Young. In calculating this index, only quantitative data are used. Of course, as discussed above, this may be a disadvantage and modern ratings try to take into account not only quantitative data, but the proposed Soft Power Index combines a fairly wide range of indicators that affect many social spheres and soft power tools. The previously obtained 
results of calculations of the Soft Power Index for Belarus can be used in the continuation of the study to analyze the objectivity of estimates of the integral indicator (Abakumova and Primierova, 2021).

Taking into account the publications devoted to the analysis of the using of soft power tools by Belarus, in particular the conclusions about the country's potential in terms of the degree of effectiveness of the use of such tools, as well as taking into account the previously considered theoretical foundations of the concept of soft power, it was decided to evaluate two ratings for Belarus according to the following groups or blocks of factors: 1) the openness (popularity) of the country: $\mathrm{z} 1$ - the number of tourists visiting the country (thousand people); z2 - revenue from international tourism (mln USD); z3 - total number of international migrants; $\mathrm{z} 4$ - the number of foreign students (ths); z5 - exports of goods and services (mln USD); 2) image of the country (or country brand): $\mathrm{x} 1$ - government spending on education ( $\%$ of GDP); $x 2$ - literacy rate (\% of people aged 15 and over); 3 - research and development costs ( $\%$ of GDP); 44 - export of high technologies ( $\%$ of the export of industrial products); x 5 - medal standings of the Winter or Summer Olympic Games; x6 - domestic companies listed abroad; $x 7$ - export of cultural property ( $\%$ of total exports).

The indicators of the country's openness to the outside world in the proposed system of indicators are the number of foreigners entering the country to live, study or as tourists, as well as the volume of exports, which measures the level of popularity and demand for goods and services by other countries. All indicators of the first block are absolute, depending on the scale of the country, which, of course, has a positive effect on the ability to softly influence other countries. The source of information on the block "Openness (popularity) of the country" is the data of the UN Statistical Division and the UN specialized agency for education, science and culture UNESCO.

The second block of indicators makes it possible to assess the level of development of education, science and technology, existing sports achievements, the number of successful enterprises, known all over the world, and interest in the cultural values of the country. The listed instruments of "soft power" are certainly capable of increasing the attractiveness and image of the country in the world arena. The World Databank and the OLYMPTEKA website served as the source of information on the indicators of the "Image of the country (or country brand)" block.

To assess the potential for the using of soft power by the countries of the world, the values of indicators for the last period presented in the listed sources (mainly 2018 and 2019) were used. When calculating integral indicators, their centered-normalized values are used.

To assess the potential for countries to use soft power tools, it is proposed to construct an integral indicator for each set of indicators, on the basis of which countries are ranked. The idea of the degree of manifestation of the latent integral property will be determined as a result of the summation of the measured indicators.

To construct an integral indicator, one of three approaches will be used: construction of an integral indicator by the principal component method; building an integral indicator based on an ordered multiple choice model; construction of an integral indicator by the expertstatistical method. To implement the above mathematical tools, the Eviews, Statistica, Stata packages are used in the work.

The openness (popularity) of the country. The informativity of the first main component is about $75 \%$, which allows us to consider the first main component as an integral indicator. The correlation coefficients of the first principal component with all the original features take on rather high values, and also have the same negative sign. This can be interpreted as follows: the greater the value of the integral indicator, the higher the level of openness (popularity) of the country, if the coefficients of the linear transformation of the initial characteristics are considered positive. The integral indicator of the level of openness (popularity) of the country is as follows: 


$$
I_{\text {Openness }}=0,41 \cdot z 1+0,49 \cdot z 2+0,47 \cdot z 3+0,47 \cdot z 4+0,4 \cdot z 5
$$

In the rating compiled for the integral indicator of the country's image, Belarus occupies 41 positions, for comparison, Russia and Ukraine occupy 9 and 24 lines of the rating, respectively. In the top 3 countries, the USA, China, Germany are located in order. If we talk in general about the countries that occupy the top lines of the ranking, then in some of these countries people from all over the world seek to settle, study or rest, and some countries are the largest exporters in the market of goods and services, which provides cases high positions.

Image of the country (or country brand). In the construction of the integral indicator, the values of indicators for 52 countries of the world took part. The level of information content of the first main component is less than $30 \%$, which does not allow considering the first main component as an integral indicator. To divide countries into homogeneous groups, the k-means method is implemented. The number of classes is determined using Ward's method using Manhattan distance, all countries are divided into four classes. The first class of countries is characterized by the highest average values of three indicators: the export of high technologies, the export of cultural property, and the number of listed domestic companies. And the lowest averages of two indicators: government spending on education and the literacy rate of people aged 15 and over. Among the first class countries are India, China, Singapore and others. The second class of countries is characterized by low averages in four indicators: research and development expenditures, high-tech exports, winter or summer Olympic medals, and the number of domestic companies listed. This class includes Belarus and, for example, countries such as Russia, Poland, Ukraine, the Baltic countries, etc. The third class of countries is characterized by the highest average value of the medal standings of the Winter or Summer Olympic Games; Germany, Canada, the Netherlands, Norway, USA, France, Switzerland are located in this class. The fourth class of countries is characterized by the highest average values of two indicators: public spending on education and spending on research and development (Australia, Austria, Belgium, Denmark, Republic of Korea, Finland, Sweden). And also by the lowest average value of exports of cultural property from total exports.

Since the classes cannot be ordered relative to each other according to the image level formed by the countries, the construction of the integral indicator was carried out using the expert-statistical method. The expert part of the information was replaced by the classifications of countries by homogeneous groups constructed by the k-means method. On the basis of the obtained estimates of the weighting coefficients of the features, it is possible to write down the type of the integral indicator characterizing the image of the country:

$$
I_{\text {Country Brand }}=16 \cdot x 1+5,2 \cdot x 2+30,8 \cdot x 3+2,8 \cdot x 4+24,2 \cdot x 5+0,2 \cdot x 6+0,5 \cdot x 7
$$

In the rating compiled for the integral indicator of the country's image, Belarus occupies 30th position, for comparison, Russia and Ukraine occupy 15th and 32nd lines of the rating, respectively. In the top 3 countries are Norway, Germany, Sweden. If we talk about the countries located at the beginning of the ranking, this is due, among other things, to the large number of medals in the 2018 Winter Olympics.

Taking into account the reasoning regarding the consistency of the ratings, it was logical to check the results obtained for the two integral indicators for at least 52 countries included in both ratings. According to the check by the Spearman test, the obtained value of the rank correlation coefficient was 0.38 , which indicates the significance of the rank correlation, the value of the confidence level was $P=0.005$. A similar result was obtained in Kendall's test: the value of the rank correlation coefficient is 0.26 , the null hypothesis is rejected because the value of the confidence level is $\mathrm{P}=0.008$. 


\section{Conclusion}

In the Republic of Belarus, the most developed is such an instrument of soft power as the country's image, which is formed mainly by relatively high government spending on education and the level of literacy of the population. The instruments of soft power associated with the openness (popularity) of the country are actively used, perhaps not always effectively. Increased spending on research and development, the export of high technologies, the export of cultural property, as well as an increase in the performance of sports achievements can be seen as potential for further strengthening the country's image. It is possible to presume a lag in terms of blocks of indicators, which could be designated as trust in the authorities, protection of rights and freedoms, the attractiveness of the business environment and the standard of living of the population.

According to the results of the assessment of soft power, taking into account the two considered blocks of indicators, the Republic of Belarus occupies the 28th position out of 62 countries. Taking into account the ratings on the two built integral indicators, Germany, the USA, Canada, France, China entered the top 5 leading countries in the use of "soft power" instruments. At the same time, it should be understood, as has already been discussed, that the considered instruments of soft power are not developed equally in the countries. Leading countries, in turn, undoubtedly influence the behavior of other countries of the world, but not by force, but by authority in the world community, earned with the help of various instruments of soft power.

Comparing the position of the Republic of Belarus in the ranking with neighboring countries, we can conclude that in terms of the overall rating it is inferior to its closest neighbors - Russia (19) and Ukraine (22), and is in a neighboring position with Poland (29). At the same time, yielding two positions to Belarus in terms of image, Ukraine has a more advantageous position in the overall rating due to the country's openness. As in Trade Edition by Bloom Consulting, Belarus took a position above the Baltic countries: Latvia (50), Lithuania (55) and Estonia (30), bypassing them due to the indicators of the level of openness. Considering the results separately for two blocks, we can conclude that there is sufficient potential for the use of soft power among the EAEU member states: Belarus is in second place in terms of the country's image (after Kazakhstan), in third place in terms of openness (inferior to Russia and Kazakhstan, the last - only one position). As a result, in the overall rating for two groups of indicators among the EAEU countries, Belarus was second only to Russia.

We can say that the effectiveness of the soft power campaign in Belarus is hampered by inconsistency in the development of the strategy. To improve a positive image, it is also necessary to balance some national interests with the wishes of the world community. Statistical and qualitative analysis testifies to the success of the Belarusian soft power strategy only in certain areas, however, the effectiveness in these areas allows Belarus to look no worse than some other countries using a wider range of soft power tools.

To confirm the reliability of the results obtained, let us turn to checking the rank correlation by comparing the results of the overall ranking with the Country Brand ranking (first consider Tourism Edition) for 61 countries, excluding Uzbekistan, which was not included in this edition. Those the conclusion about the objectivity of the rating obtained will be based on the confirmation of the consistency of the results with the known estimates from Bloom Consulting. The choice of the index was determined by the number of countries available for comparison, as well as by the fact that the integral indicator assessed the country's image and its openness (there is an intersection of the considered characteristics). According to the check by the Spearman test, the obtained value of the rank correlation coefficient was 0.71 , which indicates the significance of the rank correlation, the value of the confidence probability was $\mathrm{P}=0.000$. When considering the Trade Edition for the entire sample, the level of rank correlation is estimated lower and is 0.61 , which also indicates the 
consistency of the results obtained for the integral indicator with the considered index. However, it is clear that to a greater extent our indicator of the country's image and openness corresponds to the Tourism Edition. For reference, the rank correlation between components (Editions) of Country Brand ranking is $0.83(\mathrm{P}=0.000)$.

\section{References}

1. Schulze, J.L. (2021) Re-framing Russia's soft power in post-accession Latvia: education reform and naturalization for stateless children. Eurasian Geography and Economics, 62(3), 264-292. doi:10.1080/15387216.2020.1855997

2. Nye, J. S. (2011). The future of power. New York: PublicAffairs.

3. Ying, F. (2008) Soft power: power of attraction or confusion? Place Branding and Public Diplomacy, 4(2), 147-158.

4. Zhang, C., Wu, R. (2019). Battlefield of global ranking: How do power rivalries shape soft power index building? Global Media and China, 4(2), 179-202. doi : $10.1177 / 2059436419855876$

5. Wagner, J. (2020). Soft power and Germany's exports - First evidence from transaction data. Economics Bulletin, 40(1), 624-631.

6. Rose, A. (2016). Like Me, Buy Me: The Effect of Soft Power on Exports. Economics and Politics, 28(2), 216-232.

7. Rose, A. (2019). Soft power and exports. Review of International Economics, 27(5), 1573-1590.

8. Didier, L. (2019). Soft power and exporters behavior in international trade. Economics Bulletin, 39(4), 2595-2614.

9. Laifer, N., Kitchen, N. (2017). Making soft power work: Theory and practice in Australia's international education policy. Politics \& Policy, 45(5), 813-840.

10. Lo, W. Y. W. (2011). Soft power, university rankings and knowledge production: distinctions between hegemony and self-determination in higher education. Comparative Education, 47(2), 209-222.

11. Strożek, P., Kobierecki, M.M. (2017). Sport as a Factor of Nation Branding: A Quantitative Approach. The International Journal of the History of Sport, 34(7-8), 697 712. doi:10.1080/09523367.2017.1403901

12. Nye, J. S. (2004). Soft power: The means to success in world politics. New York: Public Affairs.

13. Hunter, A. (2009) Soft Power: China on the Global Stage. Chinese Journal of International Politics, 2(3), 373-398. doi:10.1093/cjip/pop001

14. Korolev, V., Vladimirova, A., Trunina, A. (2014) Country Branding and Soft Power Global Ratings. International Organisations Research Journal, 9(2), 209-228.

15. Pavlovskaya, S.V., Abakumova, J.G. (2020). Soft Power of Belarus. Oikonomos: journal of social market economy, 2(17), 55-62.

16. Abakumova, J.G., Primierova O.K. (2021). Globalization and Assessement of the Soft Power Potential of Belarus Using Econometric Instruments. Proceedings of the Globalization and its socio-economic consequences 2020 conference, 92. doi:10.1051/shsconf/20219208015 